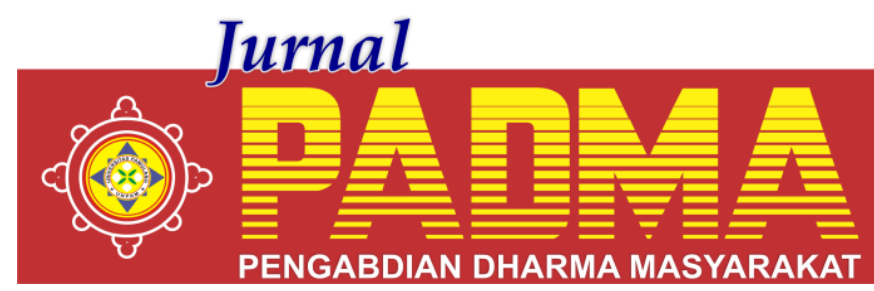

VOLUME I, NOMOR 3, JULI 2021

\title{
TANTANGAN DAN PELUANG PROFESI AKUNTAN DI ERA MILENIAL
}

\author{
1*Yunita Kurnia Shanti, ${ }^{2}$ Susi Sih Kusumawardhany \\ Universitas Pamulang, Tangerang Selatan, Banten, Indonesia \\ 1*dosen00899@unpam.ac.id, 20. dosen01244@unpam.ac.id
}

\begin{abstract}
Abstrak
Perkembangan teknologi yang semakin pesat menjadi sinyal era automasi/digitalisasi. Artinya, peran teknologi mulai menggeser kendali pekerjaan yang biasa dilakukan manusia. Potensi teknologi menggantikan peran profesi akuntan hanya menunggu waktu. Peran akuntan akan bersifat strategis dan konsultatif. Maka dari itu akuntan perlu memiliki sertifikasi misalnya fasih berteknologi, supaya mampu bertahan dalam bersaing. Seorang akuntan juga harus memiliki strategi, diantaranya penguasaan soft skill baik interpersonal skills maupun intra-personal skills, business understanding skills dan technical skills agar mampu menjawab tantangan diera digital ini. Seorang akuntan harus aware terhadap perkembangan revolusi industri 4.0 dengan melihat kesempatan yang ada. Perubahan era memang tidak bisa dihindari, maka dari itu harus selalu bisa mengontrol reaksi dan sikap terhadap perubahan tersebut agar bisa ikut maju mengikuti perkembangan zaman. Dalam sektor akuntansi, berbagai tantangan yang hadir seiring datangnya era digital tak bisa dibiarkan begitu saja, harus dipelajari dengan baik agar dapat menentukan sikap untuk mengatasinya. Fasih berteknologi merupakan salah satu kunci menghadapi tantangan di era ini. Berdasarkan fenomena tersebut, tim pengabdian kepada masyarakat Program Studi Akuntansi S1 Universitas Pamulang telah melakukan penyuluhan secara daring via aplikasi zoom bagi murid-murid SMKS Daru Roja Cinere-Depok sebagai kepedulian akan pentingnya memahami tantangan dan peluang profesi akuntan di era milenial.
\end{abstract}

Kata Kunci: Tantangan Profesi Akuntan, Peluang Profesi Akuntan

\section{Abstract}

The rapid development of technology signals the era of automation/ digitization. That is, the role of technology began to shift the control of the work commonly done by humans. The potential of technology to replace the role of the accounting profession is just a matter of time. The role of accountant will be strategic and consultative. Therefore accountants need to have certifications such as eloquent technology, in order to be able to survive in competition. An accountant must also have strategies, including mastery of soft skills both interpersonal skills and intra-personal skills, business understanding skills and technical skills in order to be able to answer the challenges of this digital age. An accountant should be aware of the development of industrial revolution 4.0 by looking at the opportunities that exist. Era change is inevitable, therefore must always be able to control the reaction and attitude to the change in order to be able to move forward with the times. In the accounting sector, various challenges that come with the coming digital era can the attitude to overcome it. Eloquence in technology is one of the key challenges in this era. Based on this phenomenon, the community service team of Accounting Study Program S1 Pamulang University has conducted online counseling via zoom application for students of SMKS Daru Roja Cinere-Depok as a concern for the importance of understanding the challenges and opportunities of the accountant profession in the millennial era.

Keywords: Challenges Of The Accountant Profession, Accountant Professional The Opportunities

\section{PENDAHULUAN}

Kehadiran Revolusi Industri 4.0 membawa perubahaan pada penyesuaian pekerjaan pada manusia, mesin, teknologi dan proses di berbagai bidang profesi, termasuk profesi akuntan. Revolusi Industri menuntut profesi akuntan untuk menyesuaikan dengan perkembangan teknologi informasi dan big data.
Menghadapi era industri termutakhir masa kini, perkembangan ekonomi digital telah membuka berbagai kemungkinan baru sekaligus meningkatkan resiko secara bersamaan. Perubahan tersebut memberikan dampak signifikan dalam perkembangan akuntansi. Di era ini, perkembangan teknologi dan inovasi seolah berkejaran dengan waktu. Inovasi-inovasi baru 
mendorong terciptanya pasar baru dan menggeser keberadaan pasar lama. Mesin dan robot pintar kini banyak mengambil peran dan seakan menguasai dunia. Pada Revolusi Industri 4.0 terjadi pergeseran yang luar biasa pada berbagai bidang ilmu dan profesi, oleh karena itu cara kerja dan praktik akuntan perlu diubah untuk meningkatkan kualitas layanan dan ekspansi global melalui komunikasi daring dan penggunaan cloud computing. Di era digital dan perkembangan teknologi seperti sekarang, arus informasi berjalan begitu cepat, teknologi internet telah mengubah pandangan seseorang dalam mendapatkan informasi, termasuk dalam dunia akuntansi bisnis. Perkembangan teknologi mengubah bisnis, menjadikan tidak banyaknya sumber daya manusia yang dibutuhkan dalam bisnis termasuk staf akuntansi. Hal ini mengakibatkan Profesi akuntan underestimate terkait dampak teknologi terhadap pekerjaan akuntan. Ini menjadikan tantangan berat yang harus dijawab.

Perkembangan teknologi yang semakin pesat menjadi sinyal era automasi/digitalisasi. Artinya, peran teknologi mulai menggeser kendali pekerjaan yang biasa dilakukan manusia. Potensi teknologi menggantikan peran profesi akuntan hanya menunggu waktu. Peran akuntan akan bersifat strategis dan konsultatif. Maka dari itu akuntan perlu memiliki sertifikasi misalnya fasih berteknologi, supaya mampu bertahan dalam bersaing. Seorang akuntan juga harus memiliki strategi, diantaranya penguasaan soft skill baik interpersonal skills maupun intra-personal skills, business understanding skills dan technical skills agar mampu menjawab tantangan diera digital ini. Seorang akuntan harus aware terhadap perkembangan revolusi industri 4.0 dengan melihat kesempatan yang ada. Perubahan era memang tidak bisa dihindari, maka dari itu harus selalu bisa mengontrol reaksi dan sikap terhadap perubahan tersebut agar bisa ikut maju mengikuti perkembangan zaman. Dalam sektor akuntansi, berbagai tantangan yang hadir seiring datangnya era digital tak bisa dibiarkan begitu saja, harus dipelajari dengan baik agar dapat menentukan sikap untuk mengatasinya. Fasih berteknologi merupakan salah satu kunci menghadapi tantangan di era ini.

Dalam masa 5 tahun kedepan dimana teknologi 5G dalam perangkat telekomunikasi sudah diadopsi secara penuh, akses internet dalam kecepatan Gigabit per detik dan perangkat keras juga manusia sudah terhubung satu sama lain baik secara IoT atau IoP, akan mengubah peran akuntan yang digantikan oleh teknologi AI (Artificial Intelligence) dan robotik dalam melakukan pekerjaan dasar akuntan yaitu mencatat transaksi, mengolah transaksi, memilah transaksi, melakukan otomatisasi pembuatan laporan keuangan sekaligus menganalisa laporan keuangan tersebut secara mandiri tanpa campur tangan manusia. Pola swakelola fungsi dasar akuntan inilah yang tentunya meningkatkan efisiensi dan efektifitas pekerjaan dan hasilnya langsung diketahui saat itu juga (real time). Banyak perusahaan yang sudah mengembangkan hal ini karena sudah didukung adanya standarisasi proses pengelolaan keuangan dan standarisasi arsitektur sistem informasi yang memadai dan sesuai tuntutan industri generasi keempat sehingga kompetensi krusial yang dibutuhkan bagi akuntan selanjutnya adalah kemampuan analisa data, mengikuti perkembangan teknologi informasi dan memperbaharui gaya kepemimpinan.

\section{METODE}

Adanya perubahan dalam Metode pelaksanaan kegiatan Pengabdian Kepada Masyarakat ini yang rencana awalnya dilakukan secara tatap muka langsung murid-murid SMKS Darul Rodja CinereDepok, tetapi karena adanya kebijakan PSBB arena wabah COVID-19 maka PKM ini dilakukan secara daring. Metode pelaksanaan kegiatan pengabdian kepada masyarakat dengan pemaparan materi yang dilakkan secara daring (jarak jauh) dengan murid-murid SMKS Darul Rodja CinereDepok menggunakan aplikasi zoom Penyelenggaraan PKM pada tanggal 28 November 2020 pukul 09.00 sd 12.00 dihadiri sekitar 25 peserta, 2 Pendamping pihak sekolah dan 2 dosen Akuntansi S1 serta 2 mahasiswa akuntansi S1 dengan narasumber Ibu Yunita Kurnia Shanti sebagai pemateri. Kegiatan PKM ini selain 
pemaparan materi dilakukan pula diskusi dan tanya jawab kepada peserta dalam pelatihan, kemudian diakhiri dengan pembagian doorprize kepada 5 peserta. Dana kegiatan Pengabdian Kepada Masyarakat berasal dari : (i) Dana dari iuran panitia (dosen) yang ikut berpartisipasi dalam kegiatan pengabdian kepada masyarakat.

\section{HASIL DAN PEMBAHASAN}

Pengabdian kepada Masyarakat (PKM) ini dilaksanakan di SMKS Darul Roja CinereDepok. PKM ini dilaksanakan secara daring via aplikasi zoom yang didalamnya terdapat kegiatan penyuluhan dengan tujuan untuk memberi pengetahuan dan pemahaman kepada murid tantangan dan peluang profeasi akuntan di era milenial, supaya murid-murid memilikibayangan kedepan apa yang harus dilakukan dalam mengapai cita-cita. Pelaksanaan penyuluhan ini mendapat dukungan penuh dari pihak mitra, yakni Kepala Sekolah dan Pemilik Yayasan SMKS Darul Rodja Cinere-Depok dengan cara menghimbau dan menghadirkan murid SMKS terutama kelas XII sebagai peserta penyuluhan walaupun dilakukan secara daring atau jarak jauh via aplikasi zoom.
Kegiatan penyuluhan ini dilaksanakan setelah sambutan dari Kepada Sekolah dan ketua pelaksana PKM yang selanjutnya dilakukan pemaparan materi dan diskusi. narasumber menyampaikan pentingnya mengetahui tantangan dan peluang profesi akuntan. Berdasarkan rumusan masalah yang telah dijelaskan dalam bab 1, maka kami akan melaksanakan PKM melalui inisiatif dosen sendiri untuk melakukan penyuluhan,penambahan wawasan, pemaparan dan memberikan motivasi bagi para siswa SMKS jurusan Akuntansi tentang pentingnya profesi akuntan dan mengetahui tantangan peluangnya. Dan untuk memenuhi permintaan dari luar yang tertuju kepadanya, perlu mengajukan surat pemberitahuan kepada Ketua LPPM dengan sepengetahuan/persetujuan Ketua Program Studi dan Dekan, dilengkapi dengan rencana kegiatan (Poposal). Ketua LPPM menerbitkan surat tugas bagi dosen yang akan melaksanakan PKM. Setelah kegiatan selesai, dosen pelaksana PKM melaporkan hasil kegiatannya, disertai bukti-bukti fisik seperti presensi peserta, handout, modul, atau bukti-bukti lain sesuai dengan jenis kegiatannya.

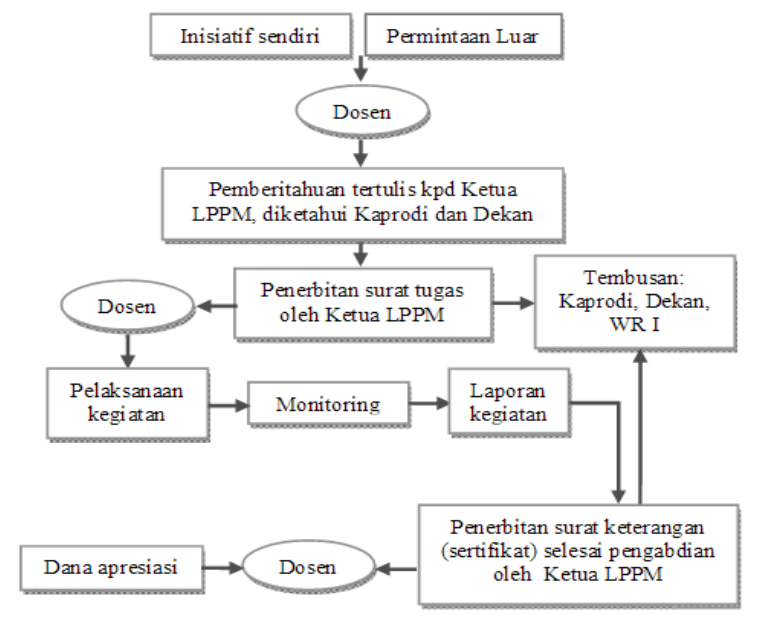

Gambar 1 : Alur Prosedur Pelaksanaan PKM

Melihat hal tersebut kami bermaksud melaksanakan pengabdian kepada masyarakat untuk memberikan wawasan ke SMKS DARUR ROJA dalam memberikan pemahaman terkait pengenalan peluang dan tantangan profesi akuntan kepada peserta didik khususnya jurusan akuntansi. Selanjutnya, pemberian motivasi untuk membentuk karakter peserta didik agar siap menghadapi masa depan untuk mencapai kesuksesan. Hasil pelaksanaan PKM yang telah dilakukan dengan peserta adalah Murid-murid SMKS Darur Roja Kelas XII Jurusan Akuntansi menunjukkan bahwa :

1. Kegiatan yang dilaksanakan untuk para siswa jurusan akuntansi adalah kegiatan untuk lebih mengenalkan kepada para siswa terkait peluang dan tantangan 
profesi akuntan. Dalam hal ini dosen membantu mereka belajar lebih mengetahui dan memahami tentang profesi akuntan untuk lebih siap memasuki dunia kerja mengingat profesi akuntan mempunya peluang yang besar dalam dunia kerja.

2. Dosen sebagai pemateri memberikan pengetahuan mengenai kewajiban seorang akuntan dalam mempertanggungjwabkan laporan keuangan yang telah dibuat dan memperluas peranan akuntan, ruang

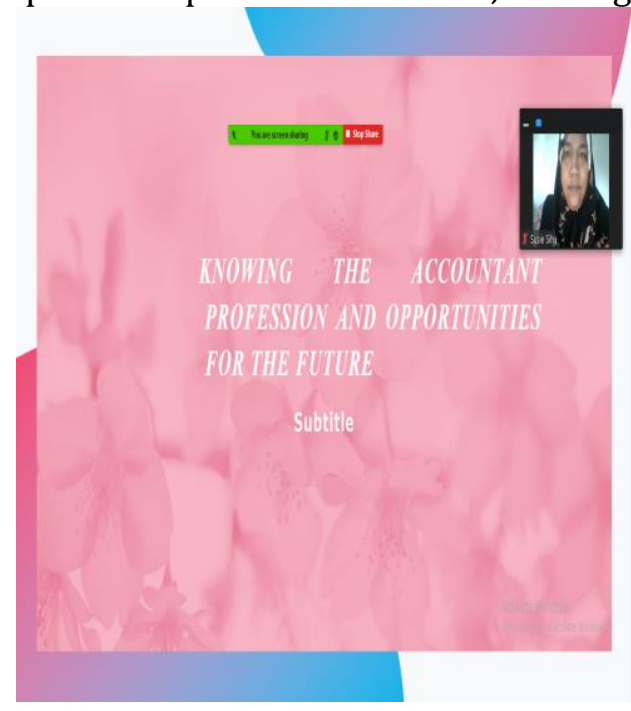

Gambar 2. Foto Pembukaan Pelatihan

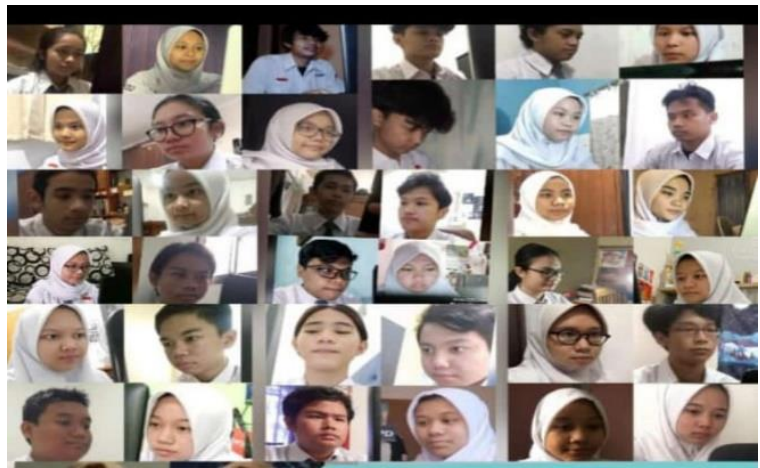

Gambar 4. Foto Pelatihan Bersama Peserta

\section{PENUTUP}

\section{Kesimpulan}

1. Tingginya kebutuhan akuntansi diberbagai sektor telah menciptakan peluang profesi dan pekerjaan yang lebih banyak di bidang ini. Akan tetapi, minimnya informasi mengenai peluang profesi yang ditawarkan oleh bidang Akuntansi membuat berbagai pihak terutama siswa/i enggan untuk melanjutkan lingkup pekerjaan akuntan publik semakin luas sehingga tidak hanya meliputi pemeriksaan akuntan dan penyusunan laporan keuangan. Para Murid-murid SMKS Darur Roja Kelas XII Jurusan Akuntansi antusias dan termotivasi untuk siap menghadapi masa depan dalam mencapai kesuksesan pada profesi akuntan. Harapan mereka bisa menjadi akuntan yang sukses sebagai generasi penerus bangsa yang memiliki moral tinggi.

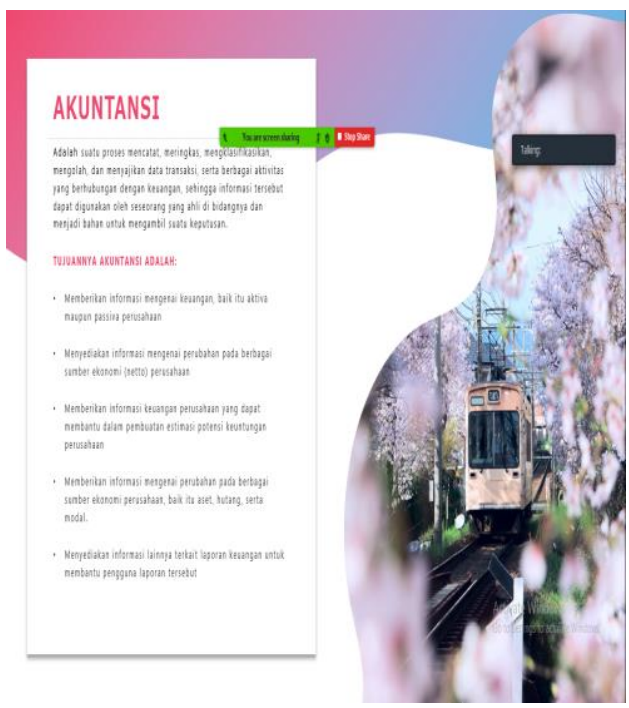

Gambar 3. Materi Pelatihan

pendidikan atau bahkan pekerjaan mereka di sector atau jurusan Akuntansi. Akuntansi hanya dianggap memberikan peluang pekerjaan dibidang pembukuan dan administrasi semata sehingga banyak yang beranggapan bahwa hanya butuh keahlian pembukuan dan matematika sederhana saja untuk menjawab tantangan tersebut.

2. Pada kenyataannya, lulusan jurusan Akuntansi menawarkan peluang profesi yang lebih beragam, contohnya adalah Akuntan baik di sector pemerintah maupun swasta. Oleh karena itu, dibutuhkan berbagai keterampilan tidak hanya pembukuan dan matematika dasar saja, akan tetapi keterampilan yang lebih dan spesifik lagi untuk dapat mengejar peluang profesi Akuntan.

\section{Saran}

Pelaksanaan kegiatan PKM ini diharapkan tetap dilakukan secara rutin untuk membantu Murid-murid SMKS Darur 
Roja Kelas XII Jurusan Akuntansi dalam memanfaatkan peluang dan tantangan profesi akuntan. Beberapa saran yang disampaikan adalah sebagai berikut:

1. Mampu menjalin kerjasama dengan pihak-pihak terkait agar bisa mendukung kegiatan yang ada sehingga fasilitasfasilitas yang dibutuhkan Murid-murid SMKS Darur Roja Kelas XII Jurusan Akuntansi bisa terpenuhi.

2. Kegiatan yang sudah ada supaya tetap dipertahankan dan ditingkatkan lagi dalam melaksanakannya, agar Muridmurid SMKS Darur Roja Kelas XII Jurusan Akuntansi paham mengenai peluang dan tantangan profesi akuntan di masa depan.

\section{DAFTAR PUSTAKA}

Absara Lara, "Faktr-faktor yang mempengaruhi mahasiswa akutansi dalam pemilihan karir sebagai Akuntan Publik", 2011, Universitas Diponegoro, Fakultas ekonomi dan Bisnis

Alek Candra Iswanto, Wahjono. 2019. Pengaruh Revolusi Industri 4.0 Terhadap Ilmu Akuntansi. INFOKAM Nomor I Th. XV/MARET/2019

Dewanti, R. N., Supriyadi, E., Sofyan, S., Sunarsi, D., Rachmansyah, B. A., \& Yani, A. (2021). Penyuluhan Dan Pelatihan Keterampilan Sablon Pigment Pasta Manual Di Karang Taruna 03 Desa
Cisauk. Jurnal PADMA: Pengabdian Dharma Masyarakat, 1(1).

http://iaiglobal.or.id/v03/beritakegiatan/detailberita-1308-tantanganprofesi-akuntan-dalam-pemulihanekonomi-nasional-pasca-pandemicovid19

https://accounting.binus.ac.id/2020/05/11/ akuntansi-dan-revolusi-industri-4-0sebuah-tantangan-profesi-akuntan-diera-digitalisasi/

https://www.blj.co.id/2019/09/17/peluang -dan-tantangan-profesi-akuntan-diera-revolusi-industri-4-0/

Profesi Akuntan Harus Beradaptasi Dengan Revolusi Industri 4.0. Kementerian Riset dan Teknologi / Badan Riset dan Inovasi Nasional. 2018

Putritama Afrida, 'Peluang dan tantangan profesi Akuntan di era Big Data “ JURNAL AKUNTANSI VOL.7 NO. 1 JUNI 2019, Universitas Sarjanawiyata Tamansiswa

Sunasi, D., Kusjono, G., \& Nuryana, I. (2019). Pelatihan Manajemen Penguasaan Kelas Dan Pembuatan Bahan Ajar Bagi Tenaga Pengajar Sukarela Taman Belajar Kreatif Mekarsari. Jurnal Pengabdian Dharma Laksana, 2(1), 4144.

UNAIR News, 2018. Akuntansi Ambil Peran dalam Revolusi Industri 4.0 . 